\title{
ERRATUM
}

\section{Erratum to: Effects of the Repeal of Missouri's Handgun Purchaser Licensing Law on Homicides}

\author{
Daniel Webster, Cassandra Kercher Crifasi, and \\ Jon S. Vernick

\section{Erratum to: J Urban Health} \\ DOI 10.1007/s11524-014-9865-8
}

The authors would like to publish this erratum to correct estimates generated from regression analyses due to errors identified in the data for certain covariates used in those analyses. The authors apologize that they did not identify the errors prior to publication. The corrected data presented below are very similar to, but are more accurate than, the findings previously published.

ABSTRACT

1. The fourth and fifth sentences should be deleted and replaced with, "Using death certificate data available through 2010, the repeal of Missouri's PTP laws was associated with an increase in the annual firearm homicide rates of 1.18 per 100,000 (+25\%) representing 68 additional firearm homicides annually, but was unrelated to changes in non-firearm homicide rates. Using Uniform Crime Reports data from police available through 2012, the law's repeal was associated with increased annual murder rates of 0.81 per 100,000 (+14 \%) representing 49 additional murders per year."

2. The last sentence should be deleted. (The corrected data from the prior sentence are integrated into the corrected sentences above.)

\section{RESULTS}

1. Table 2 should be deleted and replaced with corrected Table 2 below.

2. The last sentence of the third paragraph should be deleted and replaced with, "After controlling for changes in rates of unemployment, poverty, burglary, incarceration, and law enforcement officers along with other state laws, the estimated increase in annual firearm homicide rates associated with the repeal of Missouri's PTP handgun law was 1.18 per 100,000 population per year $(\boldsymbol{p}<.001 ; 95 \%$ confidence interval (CI) 0.92 to 1.43$)$, a $25 \%$ increase."

3. The last sentence of the 4th paragraph should read, "Regression analyses indicated that Missouri's repeal of its PTP handgun law was associated with

Webster, Crifasi, and Vernick are with the Johns Hopkins Center for Gun Policy and Research, Johns Hopkins Bloomberg School of Public Health, 624 N. Broadway, Rm. 593, Baltimore, MD 21205, USA.

Correspondence: Daniel Webster, Johns Hopkins Center for Gun Policy and Research, Johns Hopkins Bloomberg School of Public Health, 624 N. Broadway, Rm. 593, Baltimore, MD 21205, USA. (E-mail: dwebster@jhsph.edu)

The online version of the original article can be found under doi:10.1007/s11524-014-9865-8. 
no change in the age-adjusted non-firearm homicide rate $(\beta=-0.07, \boldsymbol{p}=.468$, $95 \%$ CI -0.27 to 0.12 ) and an increase in annual homicide rates for all methods of 1.08 (Table 2, $\boldsymbol{p}<.001,95 \%$ CI 0.77 to 1.40 )."

4. The last sentence of the 5 th paragraph should read, "A model which only controlled for state- and year fixed effects estimated a 1.34 increase in annual murder rates through the end of 2012 associated with the repeal of the PTP handgun law $(\beta=1.34, \boldsymbol{p}=.001,95 \%$ CI 0.58 to 2.11$)$; however, the estimated effect of the policy change was reduced to an increase of 0.81 murders per 100,000 per year after all covariates were included in the model (Table $2, \beta=0.81, \boldsymbol{p}=.004,95 \%$ CI 0.26 to 1.35 ), a $14 \%$ increase relative to the counterfactual."

5. The second sentence of the 6th paragraph should read, "New unsafe handgun bans adopted in California and Massachusetts were associated with an increase in firearm, non-firearm, and total homicide rates $(\beta=0.28$, $\boldsymbol{p}=.014,95 \%$ CI 0.06 to $0.50 ; \beta=0.19, \boldsymbol{p}=.007,95 \%$ CI 0.05 to $0.32 ; \beta=$ $0.46, \boldsymbol{p}=.008,95 \%$ CI 0.13 to 0.70$)$."

6. Supplemental Tables 1-4 should be replaced with the corrected Supplemental Tables below.

\section{DISCUSSION}

1. The last sentence of the first paragraph should read, "Our estimates suggest that the repeal of the law was associated with an additional 68 firearm homicides per year in Missouri between 2008 and 2010 and 49 additional murders per year between 2008 and 2012 than the forecasted counterfactual."

Corrected Table 2. Estimates of effect of the repeal of Missouri's permit-to-purchase handgun law from generalized least squares regression models on states' ageadjusted firearm, non-firearm, and all-cause homicide rates, 1999-2010 and murder and non-negligent manslaughter rates, 1999-2012.

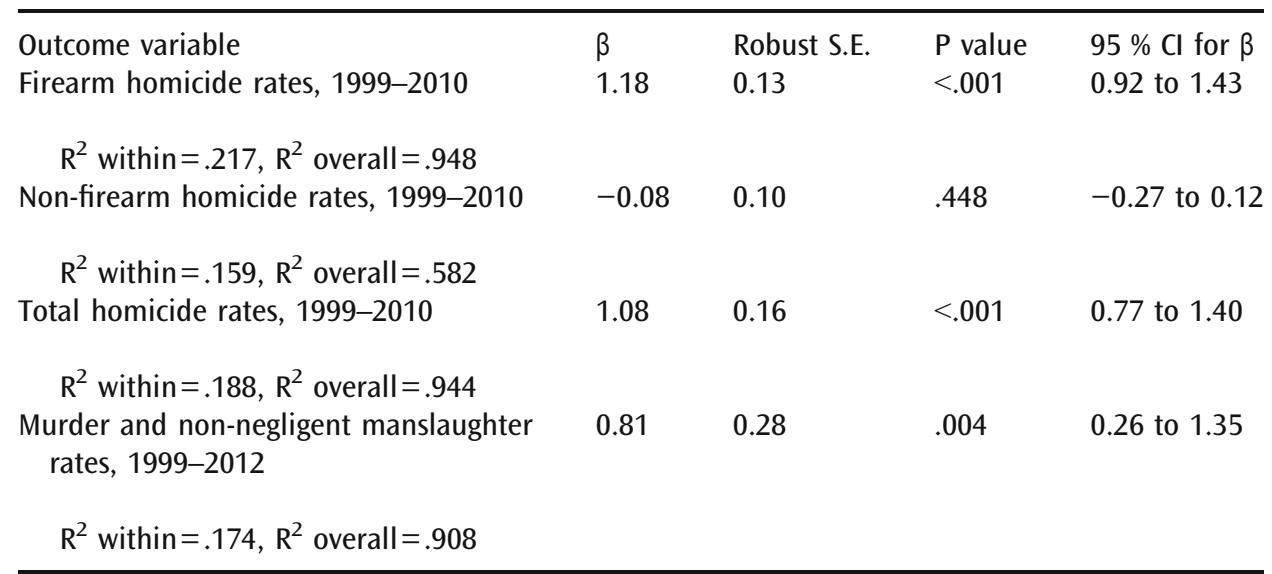

All models controlled for rates of unemployment, poverty, burglary, incarceration, law enforcement officers, "Stand Your Ground" laws, right-to-carry laws, bans of Saturday night special (junk) handguns, and firearm prohibitions of young adults with prior serious criminal offenses adjudicated in juvenile courts. Estimates for each of these covariates can be found in the Supplemental Tables. 
Corrected Supplemental Table 1. Estimates from generalized least squares regression models on states' age-adjusted firearm homicide rates, 1999-2010.

\begin{tabular}{lllll}
\hline Covariate & $\mathrm{B}$ & Robust S.E. & P value & $95 \%$ Cl for $\beta$ \\
Missouri's PTP Repeal & 1.18 & 0.13 & $<.001$ & 0.92 to 1.43 \\
Unemployment Rate & -0.047 & 0.035 & .174 & -0.12 to 0.021 \\
Burglary Rate & 0.002 & 0.0008 & .002 & 0.001 to 0.004 \\
LEOS Per Capita & -0.005 & 0.002 & .001 & -0.008 to -0.002 \\
Incarceration Rate & -0.0006 & 0.0009 & .521 & -0.002 to 0.001 \\
Percent Poverty & -0.04 & 0.02 & .078 & -0.09 to 0.005 \\
Stand Your Ground Laws & 0.16 & 0.17 & .346 & -0.18 to 0.5 \\
Juvenile Offense Restrictions & -0.08 & 0.36 & .813 & -0.79 to 0.62 \\
Saturday night Special Bans & 0.28 & 0.11 & .014 & 0.06 to 0.497 \\
Right-to-Carry Laws & 0.25 & 0.21 & .233 & -0.16 to 0.66 \\
\hline
\end{tabular}

Corrected Supplemental Table 2. Estimates from generalized least squares regression models on states' age-adjusted non-firearm homicide rates, 1999-2010.

\begin{tabular}{lllll}
\hline Covariate & B & Robust S.E. & P value & $95 \%$ Cl for $\beta$ \\
Missouri's PTP Repeal & -0.07 & 0.10 & .468 & -0.27 to 0.12 \\
Unemployment Rate & -0.007 & 0.034 & .982 & -0.0002 to 0.07 \\
Burglary Rate & 0.001 & 0.0006 & .102 & -0.0002 to 0.002 \\
LEOS Per Capita & 0.002 & 0.0015 & .192 & -0.001 to 0.005 \\
Incarceration Rate & 0.001 & 0.001 & .207 & -0.0007 to 0.003 \\
Percent Poverty & -0.032 & 0.023 & .163 & -0.08 to 0.013 \\
Stand Your Ground Laws & 0.01 & 0.1 & .910 & -0.18 to 0.20 \\
Juvenile Offense Restrictions & 0.28 & 0.29 & .319 & -0.28 to 0.84 \\
Saturday night Special Bans & 0.19 & 0.07 & .007 & 0.05 to 0.32 \\
Right-to-Carry Laws & 0.21 & 0.12 & .081 & -0.03 to 0.45 \\
\hline
\end{tabular}

Corrected Supplemental Table 3. Estimates from generalized least squares regression models on states' age-adjusted total homicide rates, 1999-2010.

\begin{tabular}{lllll}
\hline Covariate & $\beta$ & Robust S.E. & P value & $95 \%$ Cl for $\beta$ \\
Missouri's PTP Repeal & 1.08 & 0.16 & $<.001$ & 0.77 to 1.40 \\
Unemployment Rate & -0.07 & 0.047 & .140 & -0.16 to 0.023 \\
Burglary Rate & 0.003 & 0.001 & $<.001$ & 0.002 to 0.005 \\
LEOs Per Capita & -0.003 & 0.003 & .288 & -0.008 to 0.002 \\
Incarceration Rate & 0.0005 & 0.001 & .632 & -0.002 to 0.003 \\
Percent Poverty & -0.06 & 0.03 & .034 & -0.12 to -0.005 \\
Stand Your Ground Laws & 0.102 & 0.183 & .578 & -0.26 to 0.46 \\
Juvenile Offense Restrictions & 0.12 & 0.603 & .842 & -1.06 to 1.30 \\
Saturday night Special Bans & 0.41 & 0.14 & .004 & 0.13 to 0.70 \\
Right-to-Carry Laws & 0.38 & 0.23 & .102 & -0.08 to 0.84 \\
\hline
\end{tabular}

Corrected Supplemental Table 4. Estimates from generalized least squares regression models on states' murder and non-negligent manslaughter rates, 1999-2012.

\begin{tabular}{lllll}
\hline Covariate & B & Robust S.E. & P value & $95 \%$ Cl for $\beta$ \\
Missouri's PTP Repeal & 0.81 & 0.28 & .004 & 0.26 to 1.35 \\
Unemployment Rate & -0.115 & 0.063 & .066 & -0.24 to 0.008 \\
Burglary Rate & 0.008 & 0.005 & .094 & -.001 to .017
\end{tabular}




\begin{tabular}{lllll} 
LEOs Per Capita & -0.008 & 0.006 & .193 & -0.019 to 0.004 \\
Percent Poverty & -0.071 & 0.038 & .062 & -0.14 to -0.003 \\
Stand Your Ground Laws & 0.453 & 0.49 & .355 & -0.51 to 1.41 \\
Juvenile Offense Restrictions & 0.106 & 0.49 & .828 & -0.85 to 1.07 \\
Saturday night Special Bans & 0.56 & 0.307 & .071 & -0.047 to 1.16 \\
Right-to-Carry Laws & 0.58 & 0.42 & .165 & -0.24 to 1.41 \\
\hline
\end{tabular}

